\title{
THE IMPACT OF THE TOTAL TAX RATE REDUCTION ON PUBLIC SERVICES PROVIDED IN ROMANIA*
}

Adina TRANDAFIR, Lecturer Ph.D. Spiru Haret University, Faculty of Accounting and Financial Management Constanţa postdoctoral student, Institute of World Economy-Romanian Academy

Email: trandafir.adina@yahoo.co.uk

\begin{abstract}
Against the background of economic globalization, governments tend to take tax measures disadvantageous to society in order to increase the attractiveness of the business environment. A common measures for this purpose is the reduction in tax rate. According to the classical theory of tax competition such measure leads to under the provision of public goods. This article aims to show, through an econometric analysis, whether in Romania, in the period 2006-2013, reducing total tax rate had a negative impact on public services. For this, using linear regression technique, the article analysed the correlation between total tax rate and the variation in the share of the main public service spending in GDP.
\end{abstract}

Keywords: total tax rate, public services, tax collection, tax competition, social impact

JEL Classification: $\mathrm{H}_{20}, \mathrm{H}_{51}, \mathrm{H}_{52}$

\section{Introduction}

In order to attract capital, many jurisdictions appeals to fiscal measures to reduce tax rates. This problem refers to tax competition for capital attraction.

In the classical theory of tax competition it is specified that, reduction of the tax rate to attract capital may effect negative the under-provision of public services.

Taking into account the reduction in the total tax rate in Romania, in 2006-2013 period, with $6 \%$, the present article aims to analyse the impact of this reduction on the public services provided in Romania. During this period, Romania has changed its fiscal policy, harmonizing tax legislation with the acquis (Bebeşelea M., 2008).

* Acknowledgements: This paper has been financially supported within the project entitled "Horizon 2020 - Doctoral and Postdoctoral Studies: Promoting the National Interest through Excellence, Competitiveness and Responsibility in the Field of Romanian Fundamental and Applied Economic Research", contract number POSDRU/159/1.5/S/140106. This project is co-financed by European Social Fund through Sectorial Operational Programme for Human Resources Development 2007-2013. Investing in people!" 
On the background of economic globalization, tax competition between jurisdictions has increased and its negative effects were pronounced, having great repercussions at social level.

Using linear regression technique, this article analysed the correlation between the total tax rate, the total size of the accumulated funds to the state budget from tax revenues and expenditures for the most important public services in Romania in the period 2006-2013, i.e. expenditure for education, health, culture and social assistance.

In other words, the article aims to answer the question: "What is the social impact of reducing the total tax rate paid by a company in Romania in the period 2006-2013?"

Since 1972, Oates spoke of tax competition between jurisdictions to attract capital and its negative effects. In the literature these is considered classical theory of tax competition. Based on this theory, similar models were built by Zodrow and Mieszkowski (1986) and Bucovetsky, Marchad and Pestieau (1998).

\section{Literature review}

Tax competition literature began with an attempt to understand the potential problems associated with competition for capital efficiency by local governments. Oates (1972, p. 143) said that the result of tax competition may be a trend toward less efficient production of local services. In attempt to keep taxes low to attract investment, local officials may hold spending below those levels for which marginal benefits equal marginal costs, particularly for those programs that do not provide direct benefits to local businesses.

In other words, local authorities will supplement conventional measures of marginal costs with the costs arising from the negative impact of taxation on business investment. These additional costs could include wages and lower employment levels, capital losses regarding homes or other property, and reduced tax base. Their presence will reduce public spending and taxes to levels where marginal benefits will be equal to higher marginal costs.

The fact that raising taxes can increase taxed labour supply through income effects is frequently used to justify very much lower measures of the marginal welfare cost of taxes and greater public good provision than indicated by traditional, compensated analyses. Perhaps the central questions for government policy makers are what goods, in what quantities, they should provide, and what level and mix of taxes they should use to pay for them. Given the importance of these questions, one might expect reasonable agreement between economists on approaches to answering these questions. Currently, however, there are sharp differences in approaches to dealing with the income effects of taxation used to finance spending on public goods, which lead to substantial differences in policy conclusions.

As well as appearing to have major policy implications, including the income effects of taxation without those associated with public good provision has considerably complicated policy analysis. Ballard (1990), Mayshar (1990), Creedy 
(2000) and others have argued that the approach used to calculate the costs of providing government goods should differ from that used for evaluating balancedbudget changes in tax rates.

Following the Oates (1972) model, in 1986 were built two models based on this idea. It is about the model of Zodrow and Mieszkowski and the model of Wilson. According to Wilson $(1999$, p. 273), the production structure is more simple in the Zodrow and Mieszkowski's model than in its model from 1986.

The literature on tax competition, took into account most of the time, only if all regions are identical and, therefore choose the same tax rate. This separates the inefficiencies related to the overall level of public good provision efficiency and equity issues regarding the differences between tax rates and the level of public goods across regions. In this case, the cost of capital outflows from the region is offset by the benefits of capital inflows on other regions.

In the Bucovetsky, Marchand and Pestieau (1998) model is created an alternative form of policy intervention that takes into account the issue of informing the central authority. Their model includes two types of regions, different only through preferences for public goods of their residents. Following the basic model of tax competition, Bucovetsky et al. (1998) consider several regions of each type. The central authority has two policy tools: a "national tax on capital" $\mathrm{T}$ and a unique financing program, which determines the total subsidy provided for a region as a function of the tax rate chosen by the region.

Analysing models presented below, it can be concluded that there is evidence that in the basic model are found the negative effects of tax competition, however, more issues remains to be analysed in this exciting field of research. One can say that government policies are considered increasingly complex and, however governments seek to maximize rather welfare, than to engage in self-interested behaviour.

\section{Impact of tax competition on public services provided in Romania - theoretical fundamentals}

As I stated earlier, in the basic model of tax competition to attract capital is manifested its negative effects.

This paper approaches problem of the impact of reducing the total tax rate on public services provided in Romania.

Through total tax rate it is understood all amounts paid by a company as a percentage of its commercial profit earned before tax.

Romania has taken these measures to reduce the total tax rate, because according to studies undertaken by IFC and PWC (Paying Taxes 2006 to 2013), the tax rate was very high. Also, in these studies Romania is criticized for great number of taxes on work that an employer is obliged to pay.

Romania was generally below the EU average, registering a total tax rate of $48.9 \%$ in 2006 from $46.9 \%$ in 2007, $48 \%$ in $2008,44.6 \%$ in 2009, $44.9 \%$ in 2010 , $44.4 \%$ in 2011, 44.2\% in 2012 and $42.9 \%$ in 2013 (Paying taxes, 2006-2013). As can be seen, the total tax rate decreased by $6 \%$ within less than a decade. All these 
measures were taken in the context of tax competition manifested both globally and especially at the regional level in the EU.

This paper starts from the idea that tax competition through tax rates to attract capital has as negative effect the under provision of public services.

In this context, using the linear regression technique, the article aims to show the correlation between the total tax rate and public services in Romania, in the period 2006-2013 and also how influenced the decrease of this tax the revenue collections to the national budget in same period.

In the analysis carried out used a linear regression model as follows:

where:

$$
y=f(x)
$$

$$
f(x)=\alpha+\beta x
$$

where:

$y$ - dependent variable, represented in this case, by share of tax revenues in GDP, share of different categories of expenditure for public services in GDP, such as education spending (denoted Education), health (denoted Health) Culture (denoted Culture), social security (denoted Social assistance)

$\mathrm{x}$ - independent variable, represented by the total tax rate (denoted TTR) and share of tax revenues in GDP (denoted Tax collection);

$\alpha, \beta$ - parameters of the regression equation.

To estimate the parameters we used the least squares method, which requires the election of $\mathrm{c} 1$ and $\mathrm{c} 2$ as estimators of $\alpha$ and $\beta$ such that:

$$
W\left(c_{1}, c_{2}\right)=\Sigma\left(y_{i}-c_{1}-c_{2} x_{i}\right)^{2} \text { be minimal }
$$

The variables used in the model are:

Total tax rate (TTR), independent variable

Tax collection, representing the share of tax revenues in GDP, the independent variable in relation to public services and dependent variable in relation to the total tax rate

Education, representing the share of education spending in GDP in the period 2006-2013, the dependent variable

Health, representing the share of allocated expenditure for health care in GDP in the period 2006-2013, the dependent variable

Culture, representing the share of allocated expenditure for culture in GDP in the period 2006-2013, the dependent variable

Social assistance, representing the share of social expenditure in GDP in the period 2006-2013, the dependent variable

Using the LS method, I determined the value of five linear regression equations, as follows:

(1) Impact of TTR reduction on tax collection

Tax Collection $=c(1)+c(2) * T T R$ 
(2) Impact of TTR reduction and tax collection on education

Education $=c(1)+c(2) *$ Tax Collection $+c(3) * T T R$

(3) Impact of TTR reduction and tax collection on health

Health $=c(1)+c(2) *$ Tax Collection $+c(3) * T T R$

(4) Impact of TTR reduction and tax collection on culture

Culture $=c(1)+c(2) *$ Tax Collection $+c(3) * T T R$

(5) Impact of TTR reduction and tax collection on social assistance

Social as sistance $=c(1)+c(2) *$ Tax Collection $+c(3) *$ TTR

Statistical description of the variables analysed for the period 2006-2013 is shown in the table below:

Table no. 1. Statistical description of the variables

\begin{tabular}{|l|l|l|l|l|l|l|}
\hline & $\begin{array}{l}\text { TAX } \\
\text { COLLECTION }\end{array}$ & TTR & EDUCATION & HEALTH & CULTURE & $\begin{array}{l}\text { SOCIAL } \\
\text { ASSISTANCE }\end{array}$ \\
\hline Mean & 18,77500 & 45,6 & 1,11750 & 0.465 & 0.37625 & 3,64750 \\
\hline Median & 19,00000 & 44,75 & 1,12 & 0.45 & 0.38500 & 3,60000 \\
\hline Maximum & 19,50000 & 48,9 & 1,6 & 0.59 & 0.47 & 4,28000 \\
\hline Minimum & 17,60000 & 42,9 & 0.71 & 0.41 & 0.31 & 3,13000 \\
\hline Std. Dev. & 0,67560 & 2,08806 & 0.332082 & 0.05855 & 0.04868 & 0.483167 \\
\hline Skewness & $-0,54492$ & 0.44387 & 0.120344 & 1,23922 & 0.56139 & 0.134135 \\
\hline Kurtosis & 2,06519 & 1,84590 & 1,58559 & 3,62271 & 2,95609 & 1,37743 \\
\hline Jarque-Bera & 0.687201 & 0.70667 & 0.686158 & 2,17682 & 0.42086 & 0.901570 \\
\hline Probability & 0.709212 & 0.70233 & 0.70958 & 0.336752 & 0.81023 & 0.637128 \\
\hline Sum & 150,20000 & 364,8 & 8,94 & 3,72 & 3,01000 & 29,18 \\
\hline Sum Sq. Dev. & 3,19500 & 3,05200 & 0.771950 & 0.024000 & 0.01658 & 1,63415 \\
\hline
\end{tabular}

Source: own calculations using Eviews program of the empirical data from Statistical Yearbook of Romania and the consolidated budgets of Romania.

\section{Impact of total tax rate reduction on public services provided in Romania - econometric evidences}

In the classical theory of fiscal competition filed by Oates (1972) states that competition among governments to attract capital may lead to less efficient levels of public goods. In an attempt to reduce the tax rate and keep it at low to attract investment, officials will take measures to supplement marginal costs with the costs arising from the negative impact of taxation on investment. Oates (1972) 
states that such behaviour is inefficient, does not lead to a competitive advantage, and communities have lost, not only because under provision of public goods, but also due to other effects such as lower levels of wages and employment.

Based on this idea, we built a model to show the correlation between TTR and the evolution of expenditures for major public services in Romania, in the period 2006-2013. Also in this analysis is taken into account and the correlation between changes TTR and tax revenue collection to the state budget (captured here as the share of tax revenues in GDP), and the correlation between this indicator and the main expense of public services in Romania. It is worth noting that, TTR had a downward trend, dropping in less than a decade by 6 per cent.

Using regression technique to analyse the impact of changes in TTR and income tax on major public services provided in Romania in the period 2006-2013, we obtained the following results for the variables linear regression equations:

Impact of TTR reduction on tax collection

Table no. 2. Correlation between TTR and tax collection

\begin{tabular}{|c|c|c|c|c|}
\hline \multicolumn{5}{|c|}{$\begin{array}{l}\text { Dependent Variable: TAX_COLLECTION } \\
\text { Method: Least Squares } \\
\text { Sample: } 20062013 \\
\text { Included observations: } 8 \\
\text { TAX_COLLECTION=C(1)+C(2)*TTR }\end{array}$} \\
\hline & Coefficient & Std. Error & $\mathrm{t}$-Statistic & Prob. \\
\hline $\mathrm{C}(1)$ & 18,61065 & 6,02842 & 3,08715 & 0,0215 \\
\hline$C(2)$ & 0,003604 & 0,132081 & 0,02729 & 0,9791 \\
\hline R-squared & 0,00012 & \multicolumn{2}{|c|}{ Mean dependent var } & 18,77500 \\
\hline Adjusted R-squared & $-0,16652$ & \multicolumn{2}{|c|}{ S.D. dependent var } & 0,675595 \\
\hline S.E. of regression & 0,72968 & \multicolumn{2}{|c|}{ Akaike info criterion } & 2,41990 \\
\hline Sum squared resid & 3,19460 & \multicolumn{2}{|c|}{ Schwarz criterion } & 2,43976 \\
\hline Log likelihood & $-7,67959$ & \multicolumn{2}{|c|}{ Durbin-Watson stat } & 1,17625 \\
\hline
\end{tabular}

Source: own calculations using Eviews program of the empirical data from Statistical Yearbook of Romania (www.insse.ro) and the consolidated budgets of Romania.

$$
\text { Tax Collection }=18,61+0,004 * \mathrm{TTR}
$$

The relationship between TTR and tax revenues, in the econometric point of view, is a direct one, indicating a change of $0.004 \%$ of tax revenues in a change of $1 \%$ of TTR. The coefficient of determination for the regression shows that $0.012 \%$ of the variation in the share of tax revenues in GDP is explained by TTR changes. 
From an economic perspective, the link between tax revenues and TTR is a direct one. Decreased TTR should determine the change in the same direction in the cashing from tax revenue to the state budget. The low percentage that explain the tax revenues change caused by TTR changes is caused by the fact that TTR have not a high share in total tax revenues.

Impact of TTR reduction and tax collection on education

Table no. 3. Correlation between TTR, tax collection and education

\begin{tabular}{|c|c|c|c|c|}
\hline \multicolumn{5}{|c|}{$\begin{array}{l}\text { Dependent Variable: EDUCATION } \\
\text { Method: Least Squares } \\
\text { Sample: } 20062013 \\
\text { Included observations: } 8 \\
\text { EDUCATION=C(1)+C(2)*TAX_COLLECTION+C(3)*TTR }\end{array}$} \\
\hline & Coefficient & Std. Error & t-Statistic & Prob. \\
\hline $\mathrm{C}(1)$ & $-1,83430$ & 3,42372 & -0.535762 & 0.6151 \\
\hline $\mathrm{C}(2)$ & -0.119891 & 0.144112 & -0.831924 & 0.4434 \\
\hline $\mathrm{C}(3)$ & 0.114095 & 0.046628 & 2,44694 & 0.0582 \\
\hline R-squared & 0.570265 & \multicolumn{2}{|c|}{ Mean dependent var } & 1,11750 \\
\hline Adjusted R-squared & 0.398371 & \multicolumn{2}{|c|}{ S.D. dependent var } & 0.332082 \\
\hline S.E. of regression & 0.257579 & \multicolumn{2}{|c|}{ Akaike info criterion } & 0.405014 \\
\hline Sum squared resid & 0.331734 & \multicolumn{2}{|c|}{ Schwarz criterion } & 0.434804 \\
\hline Log likelihood & 13,79945 & \multicolumn{2}{|c|}{ Durbin-Watson stat } & 2,20492 \\
\hline
\end{tabular}

Source: own calculations using Eviews program of the empirical data from Statistical Yearbook of Romania (www.insse.ro) and the consolidated budgets of Romania (www.mfinante.ro/execbug.html)

\section{Education $=-1,83-0,12 *$ Tax Collection $+0,12 * \mathrm{TTR}$}

The relationship between tax revenues and education expenditure, in the econometric point of view, is an indirect one, indicating a change in the opposite direction of their $0.12 \%$ to $1 \%$ change in the share of tax revenues in GDP. The relationship between TTR and education expenditure is a direct one, indicating a $0.12 \%$ change in education expenditure to a change of $1 \%$ of TTR. The coefficient of determination for the regression showed that $57 \%$ of the variation in the share of education expenditure in GDP is explained by the share of tax revenues in GDP change and the TTR.

From an economic perspective, the link between tax revenues and expenditure education would be a direct one and depending on social programs for the period analysed and the relationship between education expenditure and TTR is 
a direct one. Decreased TTR leads to lower costs for education, confirming the conclusions of the classical theory of tax competition, the under provision of public goods.

Impact of TTR reduction and tax collection on health

Table no. 4. Correlation between TTR, tax collection and health

\begin{tabular}{|c|c|c|c|c|}
\hline \multicolumn{5}{|c|}{$\begin{array}{l}\text { Dependent Variable: HEALTH } \\
\text { Method: Least Squares } \\
\text { Sample: } 20062013 \\
\text { Included observations: } 8 \\
\text { HEALTH=C(1)+C(2)*TAX_COLLECTION+C(3)*TTR }\end{array}$} \\
\hline & Coefficient & Std. Error & t-Statistic & Prob. \\
\hline $\mathrm{C}(1)$ & 1,63252 & 0.745017 & 2,19125 & 0.0800 \\
\hline $\mathrm{C}(2)$ & -0.030220 & 0.031360 & -0.963655 & 0.3795 \\
\hline$C(3)$ & -0.013161 & 0.010146 & $-1,29711$ & 0.2512 \\
\hline R-squared & 0.345491 & \multicolumn{2}{|c|}{ Mean dependent var } & 0.4650 \\
\hline Adjusted R-squared & 0.083687 & \multicolumn{2}{|c|}{ S.D. dependent var } & 0.058554 \\
\hline S.E. of regression & 0.056050 & \multicolumn{2}{|c|}{ Akaike info criterion } & $-2,64514$ \\
\hline Sum squared resid & 0.015708 & \multicolumn{2}{|c|}{ Schwarz criterion } & $-2,61535$ \\
\hline Log likelihood & 13,58054 & \multicolumn{2}{|c|}{ Durbin-Watson stat } & 1,67128 \\
\hline
\end{tabular}

Source: own calculations using Eviews program of the empirical data from Statistical Yearbook of Romania (www.insse.ro) and the consolidated budgets of Romania (www.mfinante.ro/execbug.html)

\section{Health $=1,63-0,03 *$ Tax Collection $-0,013 *$ TTR}

The relationship between tax revenues and health expenditure, the econometric point of view, is an indirect one, indicating a change in the opposite direction of their $0.03 \%$ to $1 \%$ change in the share of tax revenues in GDP. The relationship between TTR and health expenditure is one indirect, indicating a change of $0.013 \%$ of health spending in a change of $1 \%$ of TTR. The determination coefficient for the regression shows that $34.55 \%$ of the variation of health expenditures share in GDP is explained by the change in the share of tax revenues in GDP and the TTR.

From an economic perspective, the link between tax revenues and health expenditure can be a direct one and depending on public programs for the period analysed and the relationship between health expenditure and TTR is the same direct. Decreased TTR should lead to lower health expenditures. 
Impact of TTR reduction and tax collection on culture

Table no. 5. Correlation between TTR, tax collection and culture

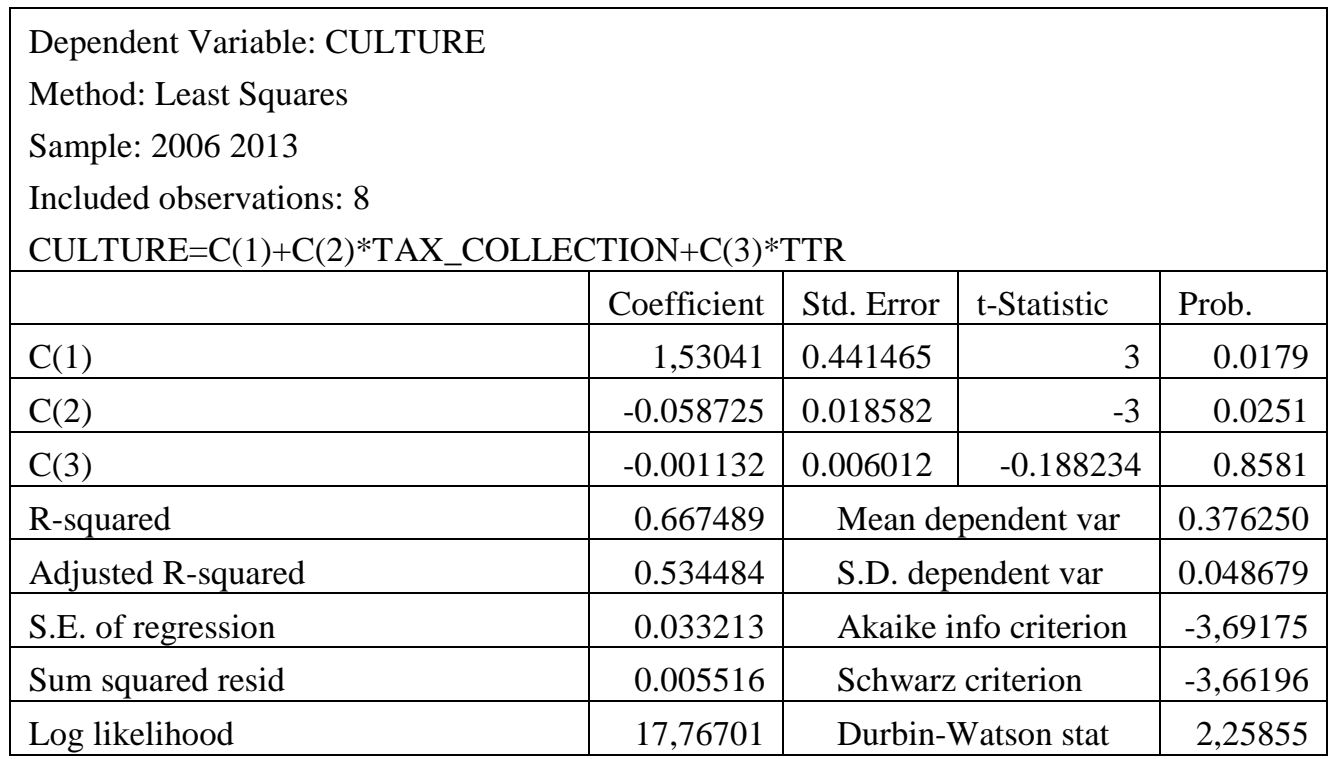

Source: own calculations using Eviews program of the empirical data from Statistical Yearbook of Romania (www.insse.ro) and the consolidated budgets of Romania (www.mfinante.ro/execbug.html)

\section{Culture $=1,53-0,059:$ Tax Collection $-0,001 \mathrm{*TTR}$}

The relationship between tax revenues and culture expenditures from econometric point of view is an indirect one, indicating a change in their reverse about $0.06 \%$ to $1 \%$ change in the share of tax revenues in GDP. The relationship between TTR and culture is one indirect costs, indicating a change of $0.001 \%$ of the spending culture in a change of $1 \%$ of TTR. The determination coefficient for the regression shows that $66.75 \%$ of the variation in expenditures for culture is explained by the change in GDP share of tax revenues in GDP and the TTR.

From an economic perspective, the link between tax revenues and spending for culture should be a direct one if we look at the problem by the fact that more money in the budget means more money allocated to social programs, and the link between spending on culture and TTR is the same direct. Decreased TTR should lead to lower costs for culture. 
Impact of TTR reduction and tax collection on social assistance

Table no. 6. Correlation between TTR, tax collection and social assistance

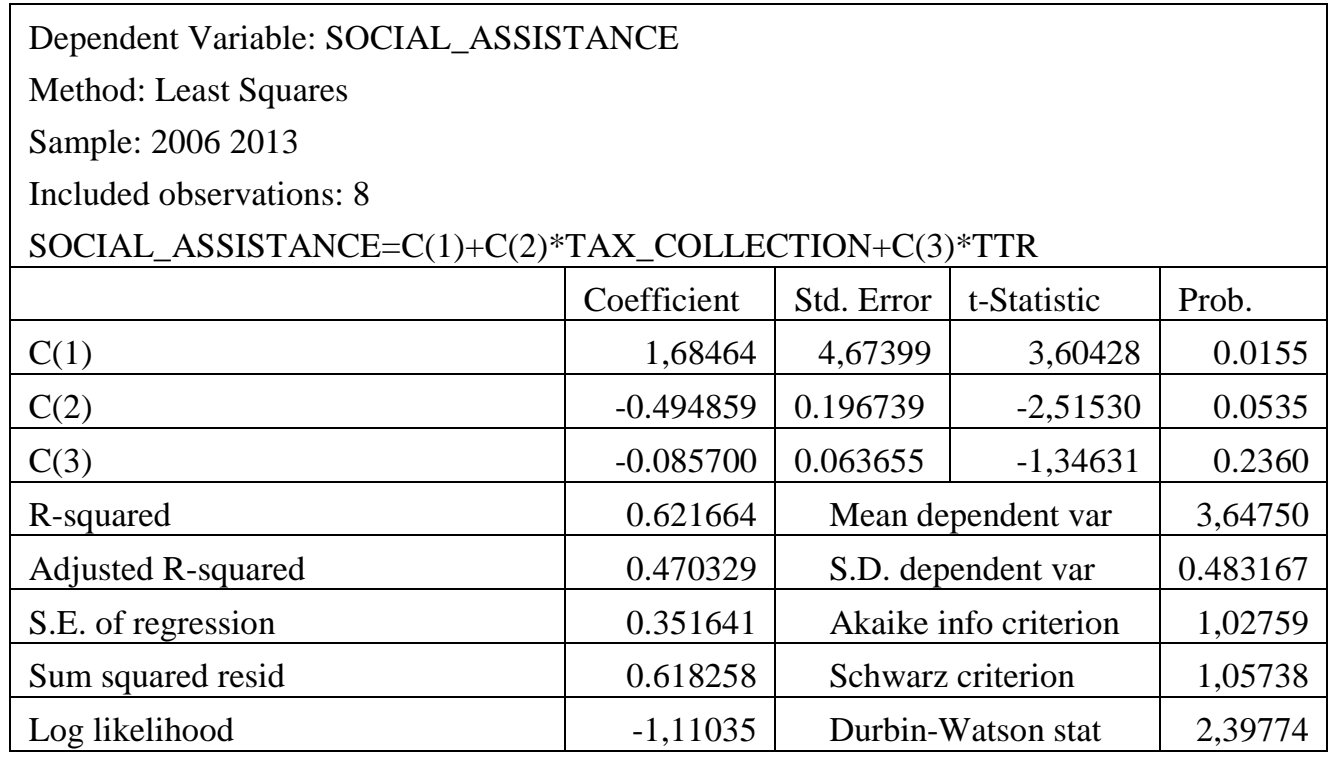

Source: own calculations using Eviews program of the empirical data from Statistical Yearbook of Romania (www.insse.ro) and the consolidated budgets of Romania (www.mfinante.ro/execbug.html)

\section{Social as sistance $=1,68-0,49 *$ Tax Collection $-0,09 *$ TTR}

The relationship between tax revenues and spending for social assistance, the econometric point of view, is an indirect one, indicating a change in the opposite direction of their $0.49 \%$ to $1 \%$ change in the share of tax revenues in GDP. The relationship between TTR and social spending is all indirect one, indicating a change of $0.09 \%$ of social spending to a change of $1 \%$ of TTR. The determination coefficient for the regression shows that $62.16 \%$ of the variation in expenditures for social change in GDP is explained by the share of tax revenues in GDP and the TTR.

From an economic perspective, the link between tax revenues and spending for social TTR should be a direct one and depending on the period analysed social programs and community needs analysis.

The econometric results are explained by the fact that in analyse it was considered only one element of tax revenues, such as corporation tax and in the transition economies, as is that of Romania, the biggest share in tax revenues formation have consumption taxes. 


\section{Conclusions}

Impact analysis of TTR reduction in the period 2006-2013 in order to increase the attractiveness of the Romanian business environment, on collection of tax revenues to the state budget and the delivery of public services has led to the following results:

- The link between the share of tax revenues in GDP and TTR is a direct one, reflecting a variation of $0.003 \%$ of tax revenues in a change of $1 \%$ of the TTR

- The correlation between tax revenues and spending for education is a indirect one, reflecting a reverse variation of them of $0.119 \%$ for a variation of $1 \%$ of tax collection and the connection between TTR and education spending is a direct one, indicating a change in $0.114 \%$ the same direction to their change for $1 \%$ of TTR

- The correlation between tax revenues, TTR and health expenditure is a indirect one, reflecting a reverse variation of them of $0.03 \%$ for a variation of $1 \%$ of tax collection and a change of $0.013 \%$ of their change for $1 \%$ of TTR

- The correlation between tax revenues, TTR and culture expenditures is a indirect one, reflecting a reverse variation of them of $0.06 \%$ for a variation of $1 \%$ of tax collection and a change of $0.001 \%$ of their change for $1 \%$ of TTR

- The correlation between tax revenues, TTR and spending for social assistance is a indirect one, reflecting a reverse variation of them of $0.495 \%$ for a variation of $1 \%$ of tax collection and a change of $0.086 \%$ of their change of $1 \%$ TTR

The determination coefficient for the regression equations presented in the previous chapter, shows that:

- $0.012 \%$ of the tax revenues variation is explained by the variation of TTR.

- $57 \%$ of the education expenditure variation is explained by variation of tax collection and TTR

- $34,55 \%$ of the health expenditure variation is explained by variation of tax collection and TTR

- $66,75 \%$ of the culture expenditure variation is explained by variation of tax collection and TTR

- $62,17 \%$ of the social assistance expenditure variation is explained by variation of tax collection and TTR

Analysing the results we conclude that the reduction in the total tax rate in the period 2006-2013, according to econometric calculations not greatly influenced nor in the expected direction, providing public services in Romania.

Therefore, in our country, in the analysed period showed no adverse effects of the classical theory of tax competition, i.e. reducing the tax rate in order to attract capital has not led to an under supply of public goods and services.

From the economic point of view these results are explained by the following aspects: the share of corporation tax revenues in total tax revenue is not very high compared to the consumption tax in our country, the allocation of funds for public 
services is influenced not only by total fund size available, but also by the public programs and the community needs.

For more relevant outcomes, in the future research we will consider the influence of consumption taxes on the provision of public services in Romania, considering the recent increases excise duty announced in our country.

\section{REFERENCES}

[1] Ballard, C. (1990), "Marginal welfare cost calculations: differential analysis versus balanced budget analysis", Journal of Public Economics, 41: 263-276.

[2] Bebeşelea, M. (2008), "The financial-accounting treatment of taxes", Annals of Spiru Haret University- Economics Series, 8(1): 53-62

[3] Bucovetsky S., Marchand M. and Pestieau P. (1998), "Tax Competition and the Revelation of Preferences for Public Expenditure", Journal of Urban Economics 44: 367-390.

[4] Creedy, J. (2000), "Measuring welfare changes and the excess burden of taxation", Bulletin of Economic Research, 52(1): 1-47.

[5] Mayshar, J. (1990), "On measures of excess burden and their interpretation", Journal of Public Economics, 43: 263-289.

[6] Oates W.E. (1972), Fiscal Federalism, New York: Harcourt Brace Jovanovich

[7] Wilson J. (1999), "Theories of tax competition", National Tax Journal, 52: 269-304

[8] Zodrow G. and Mieszkowski P. (1986), "Pigou, Tiebout, property taxation and the under provision of local public goods", Journal of Urban Economics, 19: 356-370.

[9] *** www.insse.ro

[10] *** www.mfinante.ro/execbug.html 